\title{
Comunicação
}

[Communication]

\section{Hermafroditismo em jabuti piranga (Geochelone carbonaria)}

\author{
[Hermaphroditism in jabuti piranga (Geochelone carbonaria)]
}

\author{
A.M. Conceição ${ }^{1}$, B. M. Almeida ${ }^{2}$, M.T.R. Brasileiro ${ }^{3}$, L.E.D. Barros ${ }^{4}$, S.A. Wiltshire ${ }^{4}$, \\ C.A.P. Sarmento ${ }^{5}$ \\ ${ }^{1}$ Aluno de pós-graduação - UFS - Aracaju, SE \\ ${ }^{2}$ Laboratório de Patologia Veterinária - FPD - Aracaju, SE \\ ${ }^{3}$ Laboratório de Parasitologia Veterinária - FPD - Aracaju, SE \\ ${ }^{4}$ Aluno de graduação - FPD - Aracaju, SE \\ ${ }^{5}$ Aluno de pós-graduação - FMVZ-USP - São Paulo, SP
}

Os quelônios, que surgiram há cerca de 200 milhões de anos, compreendem os cágados, jabutis e tartarugas e estão classificados na classe Reptelia (Alderton, 1986; Obsts et al., 1988). Diferenciam-se de outros répteis por apresentarem casco rígido que os protege de predadores, das variações climáticas e das pressões ambientais (Goulart, 2004). Os jabutis são quelônios de hábitos terrestres, pertencentes à família Testudinidae, a segunda maior família da ordem Testudines em número de espécies (Ernst e Barbour, 1989). A espécie Geochelone carbonaria é encontrada em zonas tropicais da América do Sul: nas Guianas, Venezuela, Equador, Paraguai, Brasil e algumas ilhas do Caribe (Pritchard, 1979; Levine e Schafer, 1992).

Tendo como características as patas robustas como pilares, com cinco dedos, um casco ósseo bastante côncavo e alto, recoberto por placas córneas com manchas amareladas ao centro, recolhem o pescoço caudalmente para dentro do casco e possuem "cabeça e as patas com escamas vermelhadas, o que lhes confere o nome popular de jabuti das patas vermelhas", diferenciando-os do Geochelone denticulata que é o "jabuti de patas amarelas" (Faria e Mariana, 2001).

O dimorfismo sexual externo pode ser bastante evidente. Basicamente, o macho possui a cauda mais longa e robusta do que a da fêmea e pode apresentar a abertura cloacal em uma posição mais mediana ou mesmo no terço distal da cauda, e algumas vezes pode apresentar uma depressão em forma de calha que se inicia na abertura externa da cloaca e vai em direção ao final da cauda. Os jabutis machos, de uma maneira geral, apresentam uma concavidade evidente no plastrão que serve para facilitar a monta por sobre a fêmea (Goulart, 2004). O pênis é bem desenvolvido e consiste da glande e dois corpos cavernosos que formam uma calha por onde passa o sêmen. Diferentemente do pênis dos mamíferos, o pênis dos quelônios não possui uretra, sendo, portanto, um órgão com função unicamente copuladora.

O objetivo deste trabalho foi relatar dois casos de pseudo-hermafroditismo em jabuti piranga (Geochelone carbonaria).

Relatam-se nos anos de 2004 e 2008 dois casos de pseudo-hermafroditismo em jabutis da espécie Geochelone carbonaria, supostamente do sexo feminino, de 15 e 14 anos, oriundos de criações domiciliares do Estado de Sergipe, com o histórico de ovoposição e acesso a um ambiente de piso rígido e bastante limitado à terra. Ao exame clínico, constatou-se o peso de $5.200 \mathrm{~g}$ e $4.800 \mathrm{~g}$ e nítido pênis diminuto, com glande rudimentar (Fig. 1), além do estado de prostração e anorexia.

Os animais foram submetidos ao exame radiográfico, verificando-se a presença de ovos na cavidade celomática. Na tentativa de expulsálos, protocolos terapêuticos à base de occitocina $(5 \mathrm{UI} / \mathrm{kg}, \mathrm{IM}$, dose única) foram adotados, porém

Recebido em 20 de outubro de 2008

Aceito em 15 de setembro de 2009

E-mail: alexmedvet@hotmail.com 
apenas no primeiro caso, no ano de 2004, obtevese êxito. Entretanto, após um ano, o animal veio a óbito, sendo submetido à necropsia, que revelou a presença de um aparelho reprodutivo feminino completo: duas tubas uterinas, dois ovários, dois ovidutos e ovos em vários graus de desenvolvimento (Fig. 2).

No segundo caso, no ano de 2008, devido à intensa hiperemia e edema local, o animal foi submetido à antibioticoterapia à base de enrofloxacina $(5 \mathrm{mg} / \mathrm{kg}$, IM, SID, por cinco dias), compressas frias, flunixin meglumine $(0,5 \mathrm{mg} / \mathrm{kg}$, IM, SID, por dois dias), fluidoterapia com solução salina fisiológica $(15 \mathrm{~mL} / \mathrm{kg}, \mathrm{SC}, \mathrm{SID}$, por cinco dias) e tentativas de redução mecânica,

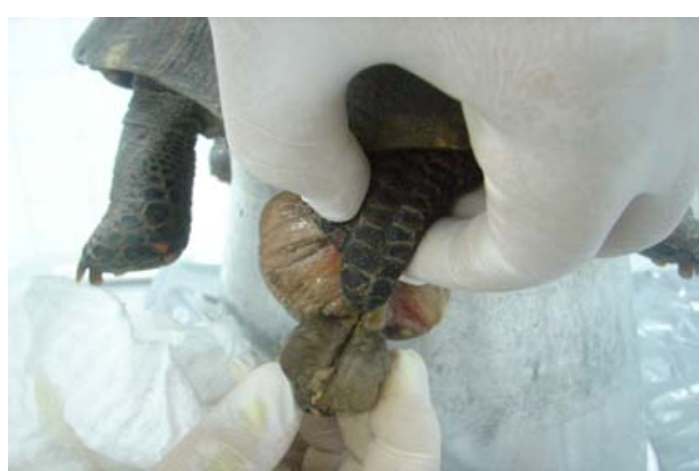

Figura 1. Presença de pênis diminuto com glande rudimentar de jabuti piranga (Geochelone carbonaria). as quais não obtiveram sucesso, optando-se, assim, pela penectomia.

Baseado na presença de genitália masculina rudimentar, associado à retenção de ovos, decidiu-se pela ressonância magnética, a fim de identificar o sistema reprodutivo interno. Após o exame minucioso, pôde-se comprovar a presença de 11 ovos em diversos estágios de desenvolvimento, entretanto não foi observada nenhuma estrutura que pudesse confirmar a existência de um aparelho reprodutor masculino (Fig. 3). O animal permaneceu com retenção de ovos, já que a proprietária não autorizou $\mathrm{o}$ tratamento cirúrgico por meio de celiotomia.

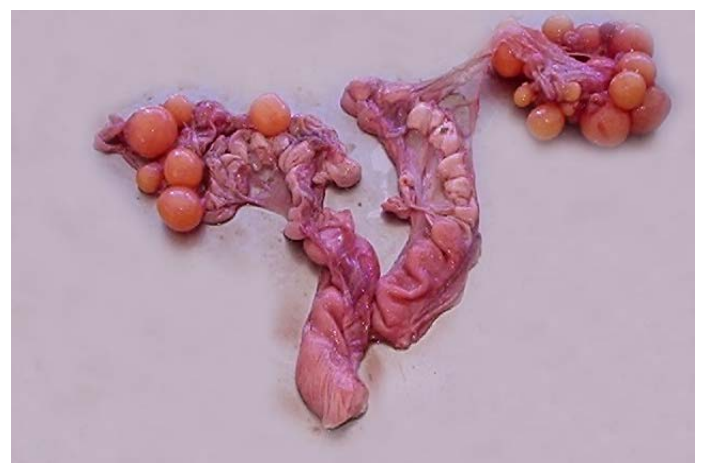

Figura 2. Aparelho reprodutor feminino completo, com duas tubas uterinas, dois ovários, dois ovidutos e ovos em vários graus de desenvolvimento do jabuti piranga (Geochelone carbonaria) observados após a necropsia.

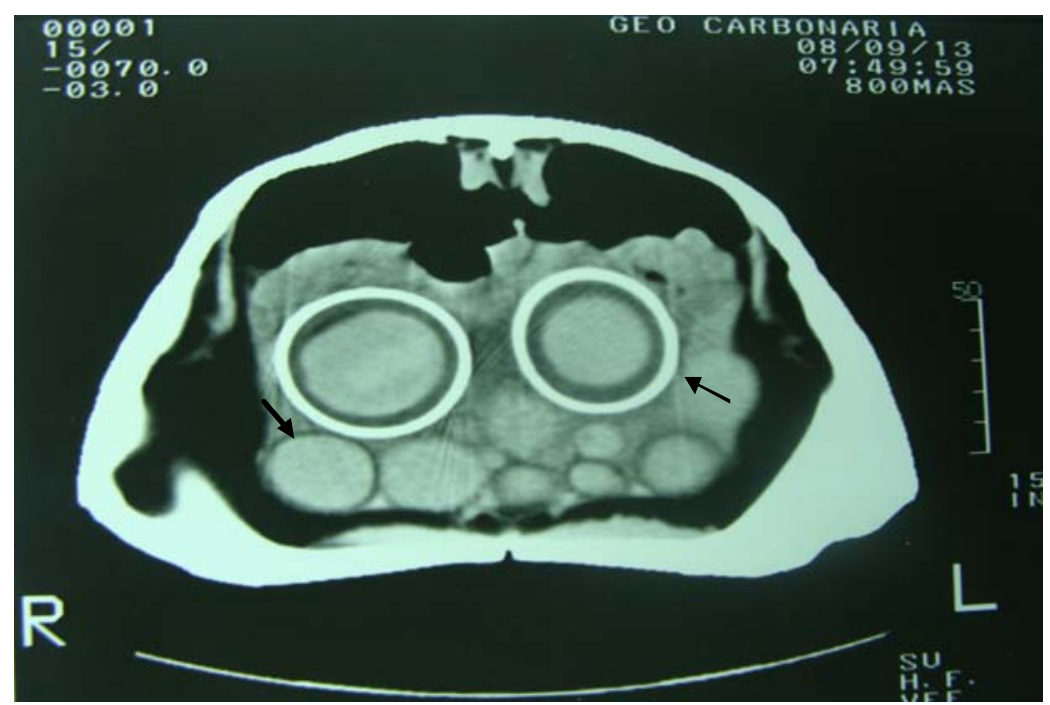

Figura 3. Imagem de ressonância magnética da cavidade celomática de um jabuti piranga (Geochelone carbonaria) com ovos em diversos estágios de desenvolvimento. 


\title{
Conceição et al.
}

O hermafroditismo tem sido relatado em outros tipos de répteis, como lagartos e cobras, porém este fato, no que diz respeito aos jabutis da espécie Geochelone carbonaria, é ainda pouco conhecido na literatura.

Sob a denominação de intersexo estão enquadrados os hermafroditas verdadeiros, os pseudo-hermafroditas e outras formas de reversão sexual (Rosnina et al., 2004). Os pseudo-hermafroditas possuem apenas um tipo de tecido gonadal e os sexos cromossômicos e gonadal são concordantes, assim, são classificados em masculinos ou femininos, dependendo do tipo de gônada presente. Os pseudo-hermafroditas femininos possuem ovários, porém apresentam algum grau de masculinização; enquanto os pseudohermafroditas masculinos possuem testículos, mas apresentam algumas características femininas, como a presença de útero e genitália externa primariamente feminina (Memon e Mickelsen, 2004)

Nos répteis, o efeito da temperatura na incubação dos ovos atua da seguinte maneira: sob temperaturas baixas $\left(20-27^{\circ} \mathrm{C}\right)$ somente o sexo feminino é formado e sob altas temperaturas $\left(30^{\circ} \mathrm{C}\right.$ e acima disso) somente o sexo oposto é formado. Entre uma pequena faixa de variação de temperatura, conhecida como faixa de temperatura crítica (geralmente entre $28-31^{\circ} \mathrm{C}$ ), ambos os sexos e, algumas vezes, intersexos são formados (Nelson et al., 2004; Mitchell et al., 2006).

O que não está completamente elucidado são os motivos que levam a este tipo de anomalia sexual. No entanto, um fato a ser levado em consideração é a elevação da temperatura da atmosfera, particularmente da troposfera, genericamente chamada de aquecimento global, que se encontra envolta em muitas dúvidas quanto as suas causas e consequências. Alterações ambientais decorrentes do aumento das temperaturas sobre animais terrestres são mediados por interações complexas entre as variáveis climáticas, relevo e vegetação, bem como morfologia, comportamento e fisiologia animal. As espécies ovíparas são mais vulneráveis às alterações climáticas principalmente na fase embrionária, uma vez que os ovos são tipicamente abandonados em locais fixos durante todo o seu desenvolvimento (Feder, 1997).

Em quelônios, com algumas exceções, a incubação dos ovos sob baixa temperatura induz a formação de machos enquanto a incubação dos ovos sob temperatura mais alta induz a formação de fêmeas. Uma das hipóteses para a determinação do sexo nos grupos especificados de répteis é a de que a temperatura poderia afetar diretamente os genes que controlam os hormônios específicos para a diferenciação das gônadas, e consequentemente, na determinação do sexo dos indivíduos. A outra hipótese é a de que a temperatura poderia influenciar na taxa de transcrição e tradução desses genes responsáveis pelos hormônios na determinação do sexo (Silva, 2008).

Pode-se comprovar, pelo quadro clínico, necropsia e ressonância magnética a ocorrência de pseudo-hermafroditismo em jabuti piranga. Estes achados têm relevância, pois na literatura não são encontrados muitos relatos de casos sobre essa patologia, tornando-a um assunto que precisa ser mais estudado e mais bem compreendido.

Palavras-chave: jabuti, Geochelone Carbonaria, hermafroditismo

\begin{abstract}
Hermaphroditism is a term used to describe animals that have genitals of both genders. This anomaly has been described in reptiles such as lizards and snakes. The jabuti species Geochelone carbonaria hull has a high and very concave bone which is covered by corneal plates with yellow spots at the center, and collect the neck caudally into the hull. Although sexual dimorphism is externally quite clear, the females have straight plastron, while the male presents a clear concave plastron that serves to facilitate the mounting and a well developed penis having the size of the animal body. However, hermaphroditism in this species can only be confirmed with additional exams.
\end{abstract}

Keywords:jabuti, Geochelone Carbonaria, hermaphroditism 


\section{REFERÊNCIAS BIBLIOGRÁFICAS}

ALDERTON, D. A Petkeepers guide to reptiles and amphibians. Blacksburg, VA: Tetra Press, 1986. $117 \mathrm{p}$.

ERNST, C.H.; BARBOUR, R.W. Turtles of the world. Washington DC: Smithsonian Institution, 1989. 313p.

FARIA, T.N.; MARIANA, A.B. Origens e ramificações das artérias aortas esquerda e dorsal do jabuti (Geochelone carbonaria, Spix, 1824). Braz. J. Vet. Res. Anim. Sci., v.38, p.155-159, 2001.

FEDER, M.E. Necrotic fruit: a novel model system for thermal ecologists. J. Therm. Biol., v.22, p.1-9, 1997.

GOULART, C.E.S. Herpetologia, herpetocultura e medicina de répteis. Rio de Janeiro: LF Livros de Veterinária, 2004. 329p.

LEVINE, D.; SCHAFER, D. Tortuga Gaz., v.28, p.1-3, 1992.

MEMON, M.A.; MICKELSEN, D.W. Distúrbios hereditários e congênitos dos sistemas reprodutivos do macho e da fêmea. In: Ettinger, S.J.; Feldman, E.C. (Eds). Tratado de medicina interna de pequenos animais. 5.ed. Rio de Janeiro: Guanabara Koogan, 2004.
MITCHEL, N.J.; NELSON, N.J.; CREE, A. et al. Support for a unique pattern of temperaturedependent sex determination in archaic reptiles: evidence from two species of tuatuara (Sphenodon). Front. Zool., v.3, art.9, 2006.

NELSON, N.J.; THOMPSON, M.B.; PLEDGER, S. et. al. Do TSD, sex ratios and nest characteristics influence the vulnerability of tatuara to global warming. Int. Congr. Ser., v.1275, p.250-257, 2004.

OBST, F.J.; RICHTER, K.; JACOB, U. The completely illustrated atlas of reptile and amphibians for the terrarium. New Jersey: TFH, 1988. 831p.

PRITCHARD, P.C.H. Encyclopedia of turtles. New Jersy: TFD, 1979. p.326-323.

SILVA, L.A. Determinação do sexo pela temperatura em reptila. Disponível em: $<$ http://www.ufv.br/dbg/bio240/Let\%EDcia_A. Silva_43662.htm>. Acessado em: 10 set. 2008 . 